Supplemental information for:

\title{
HIV Detection via a Carbon Nanotube RNA Sensor
}

Jackson D. Harvey ${ }^{1,2}$, Hanan A. Baker ${ }^{1,2}$, Michael V. Ortiz' ${ }^{1}$ Alex Kentsis ${ }^{1,2}$, Daniel A. Heller ${ }^{1,2^{*}}$

${ }^{1}$ Memorial Sloan Kettering Cancer Center, New York, NY

${ }^{2}$ Weill Cornell Medical College, New York, NY

a

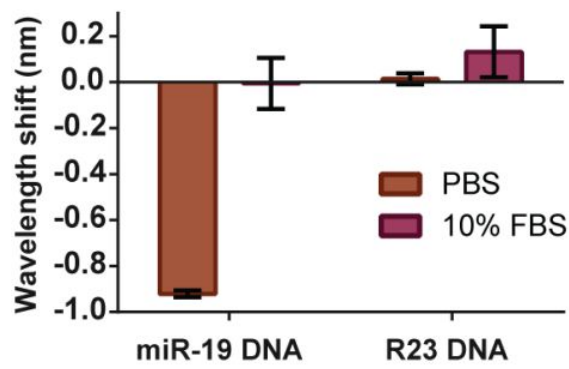

b

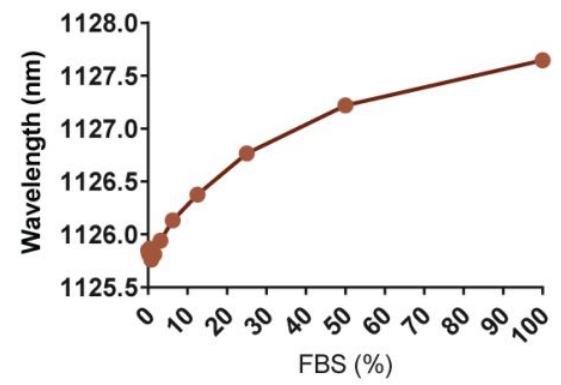

C

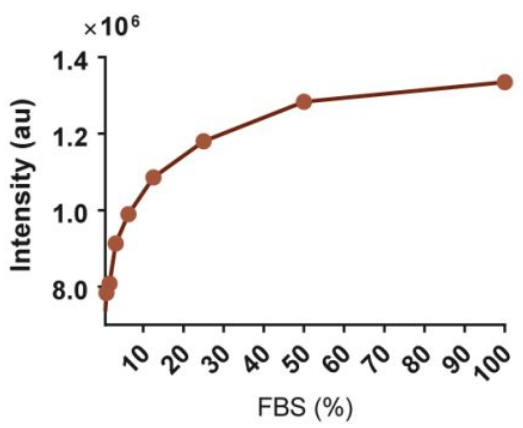

Figure S1: Impact of serum on $\mathrm{GT}_{15} \mathrm{miR} 19$ nanotube sensor function. a. Wavelength shift of $\mathrm{GT}_{15} \mathrm{mir}_{19}$ nanotube sensor after overnight incubation with $1 \mu \mathrm{M}$ target miR-19 DNA (orange) or control R23 DNA (purple) in either PBS or $10 \%$ FBS. b. Center wavelength of the $(9,4)$ chirality as a function of added fetal bovine serum (FBS) incubated overnight, c. Intensity of the $(9,4)$ chirality as a function of added fetal bovine serum (FBS) incubated overnight.

a

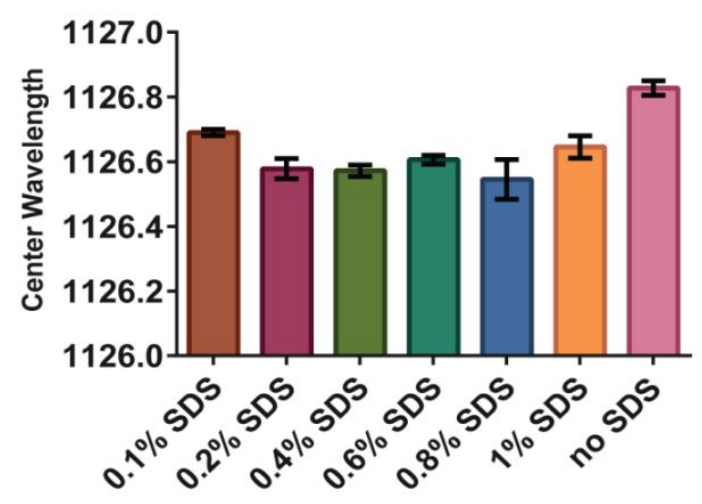

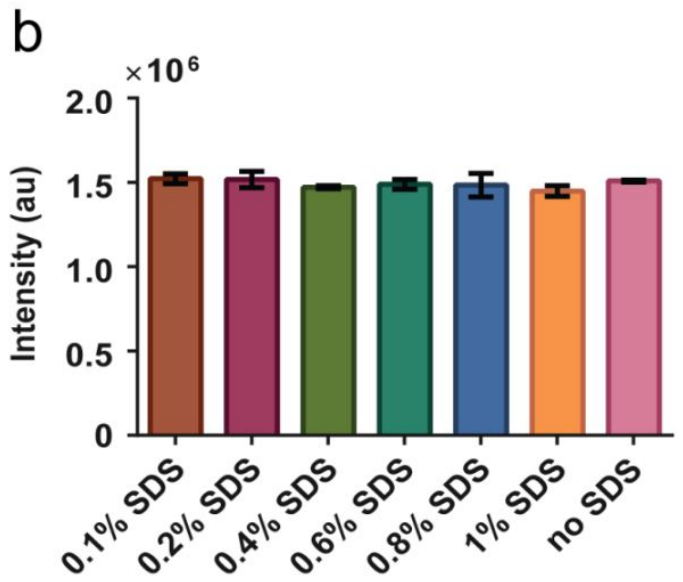

Figure S2: Baseline effects of SDS on the $\mathrm{GT}_{15} \mathrm{miR} 19$ nanotube sensor. a. Center wavelength of $\mathrm{GT}_{15}$ mir19 nanotube sensor after overnight incubation with the indicated concentration of SDS, shown for the $(9,4)$ nanotube chirality. b. Intensity of $\mathrm{GT}_{15}$ mir19 nanotube sensor after overnight incubation with the indicated concentration of SDS, shown for the $(9,4)$ nanotube chirality. Error bars represent standard deviation of technical triplicates. 

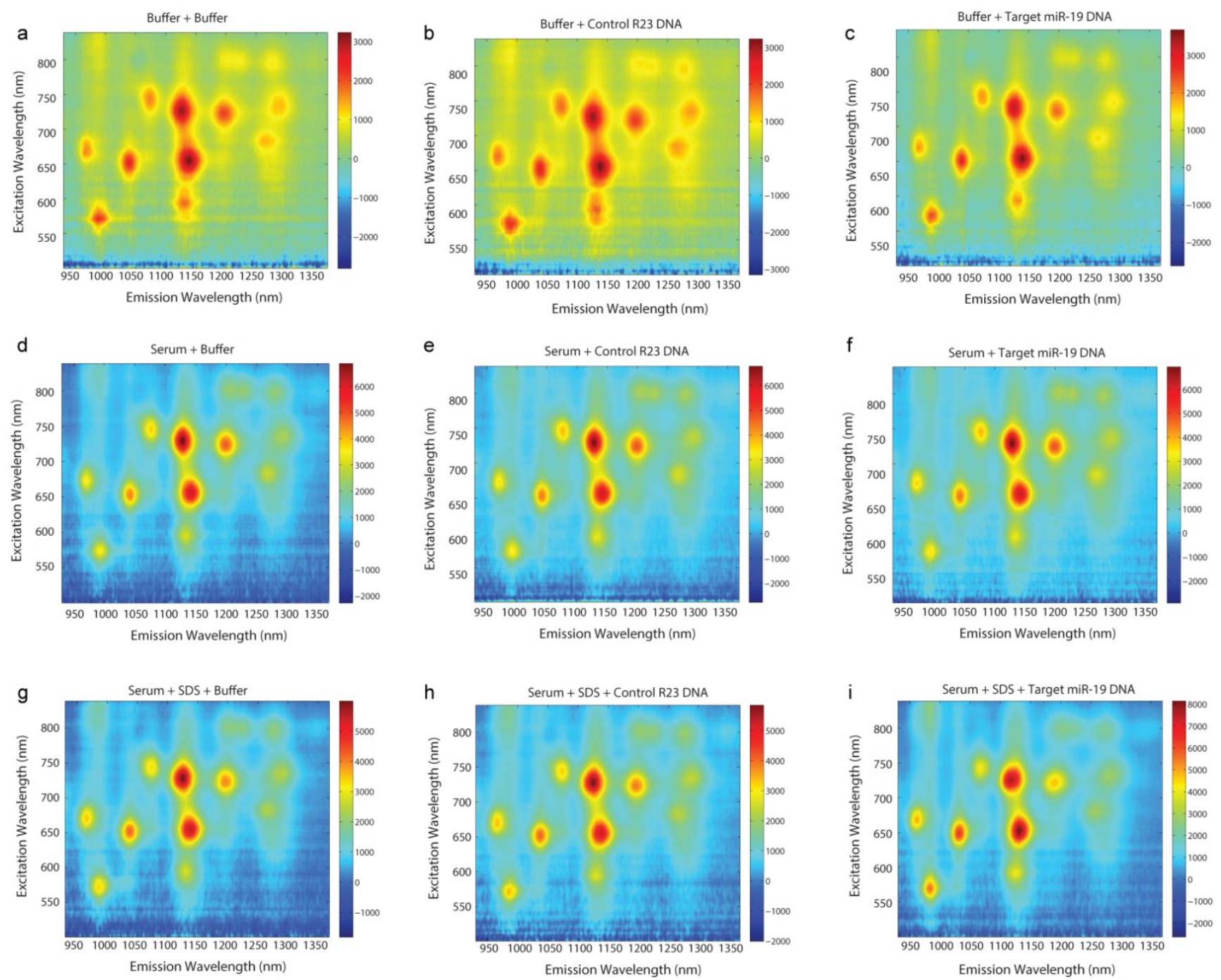

Figure S3: Modulation of the $\mathrm{GT}_{15} \mathrm{miR} 19$ nanotube sensor response in the presence of serum with and without SDS. Photoluminescence excitation/emission (PLE) spectroscopy plots of the $\mathrm{GT}_{15} \mathrm{miR} 19$ nanotube sensor incubated with a. PBS, b. PBS and control R23 DNA, c. PBS and target miR-19 DNA, d. FBS, e. FBS and control R23 DNA, f. FBS and target miR-19 DNA g. FBS and $1 \%$ SDS h. FBS, $1 \%$ SDS and control R23 DNA, and i. FBS, 1\% SDS and target miR-19 DNA. 

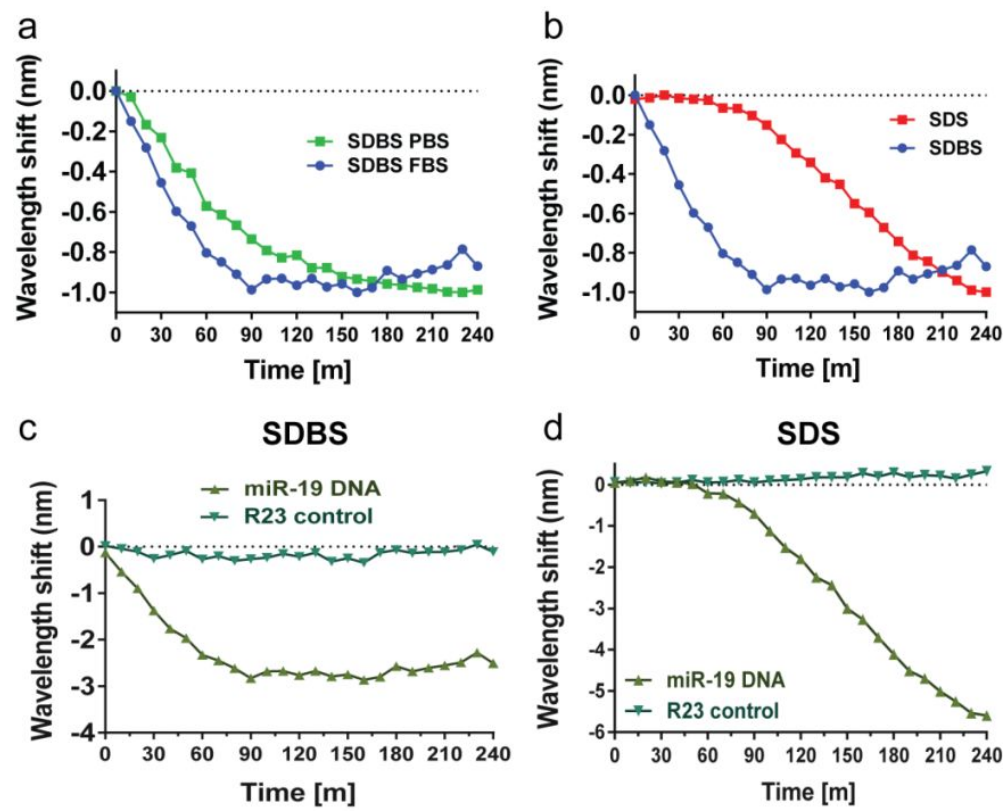

Figure S4: Kinetics of surfactant-mediated $\mathrm{GT}_{15} \mathrm{miR} 19$ nanotube sensor response. a. Normalized wavelength shift of $\mathrm{GT}_{15}$ mir19 nanotube sensor upon introduction of $1 \mu \mathrm{M}$ target miR-19 DNA in $0.2 \%$ SDBS and PBS (green) or FBS (blue). b. Wavelength shift of $\mathrm{GT}_{15}$ mir19 nanotube sensor with $1 \mu \mathrm{M}$ miR-19 target DNA in serum with $0.2 \%$ SDBS (blue) or serum with $1 \%$ SDS (red). $\mathbf{c}$ and $\mathbf{d}$. Dynamics of wavelength shift for $\mathrm{GT}_{15}$ mir19 in serum with $0.2 \%$ SDBS or $1 \%$ SDS treated with $1 \mu \mathrm{M}$ target or control DNA.

$(7,5)$
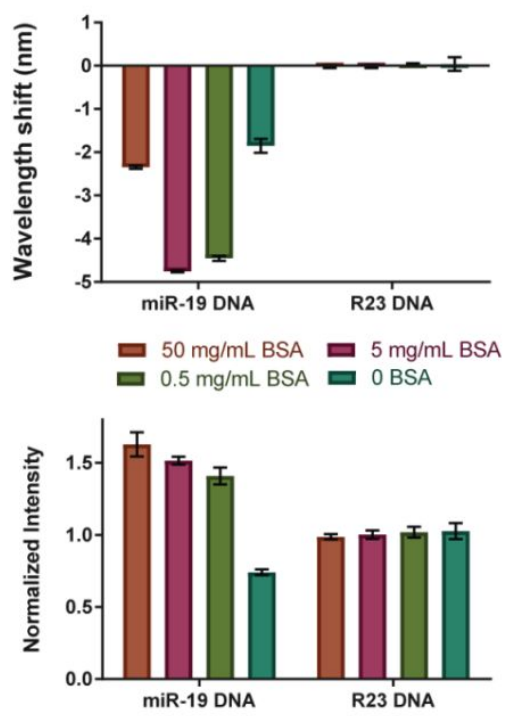

$(7,6)$
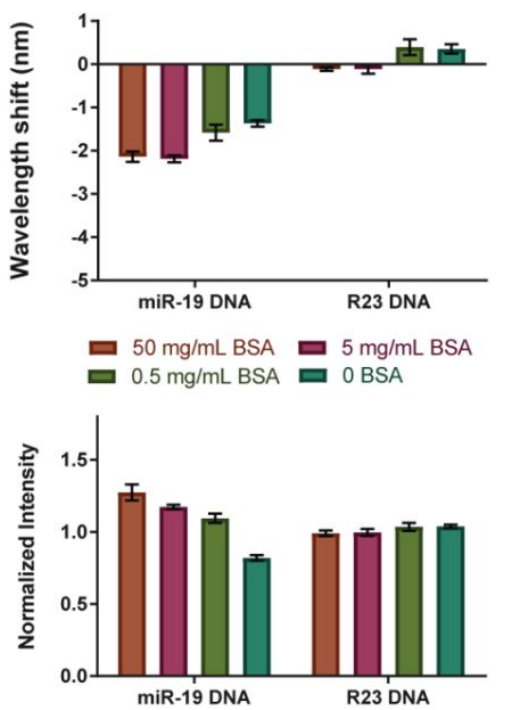

$(8,6)$
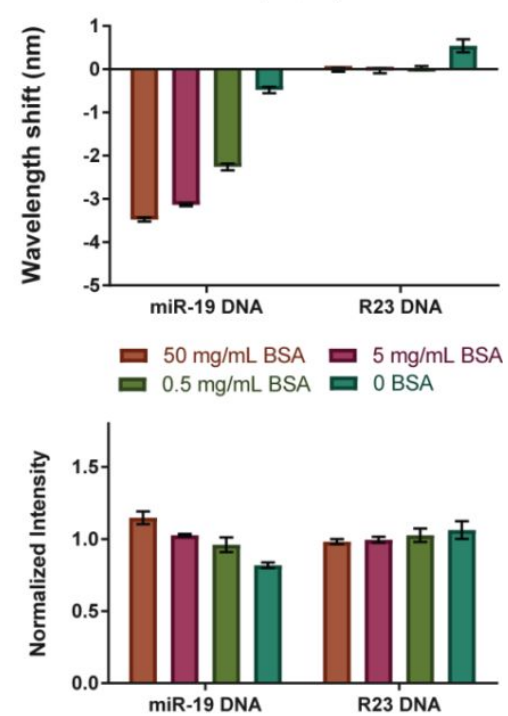

Figure S5: Chirality-specific behavior of the $\mathrm{GT}_{15} \mathrm{miR} 19$ sensor response to hybridization mediated by $\mathrm{BSA}+$ SDS. Wavelength shift (top) and intensity change (bottom) of $\mathrm{GT}_{15}$ mir19 nanotube sensor for three additional chiralities after treatment with $1 \mu \mathrm{M}$ target miR-19 DNA or control R23 DNA in PBS with $1 \%$ SDS and the indicated concentration of bovine serum albumin (BSA). 
a

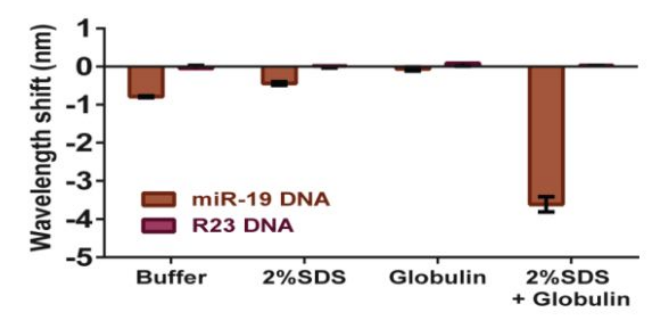

C

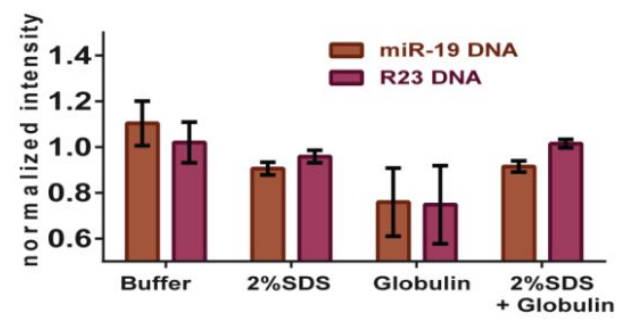

e

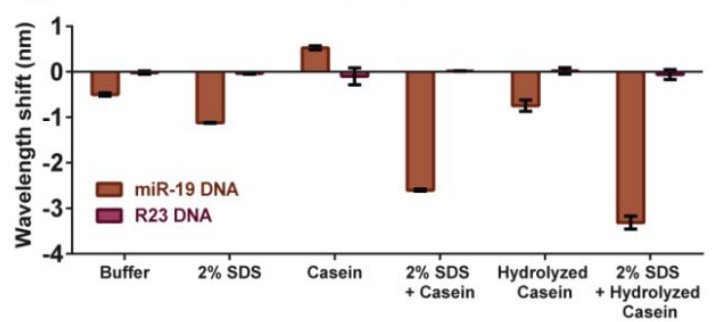

g

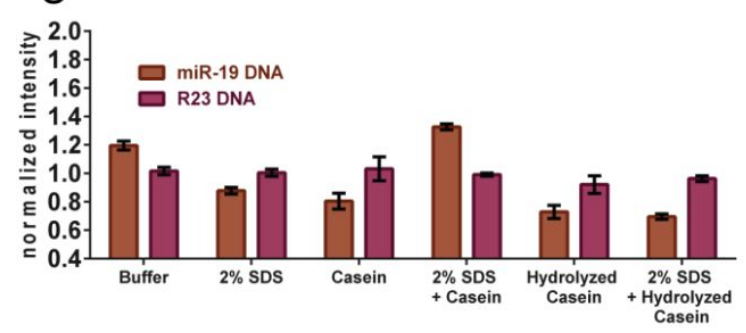

b

$(9,4)$
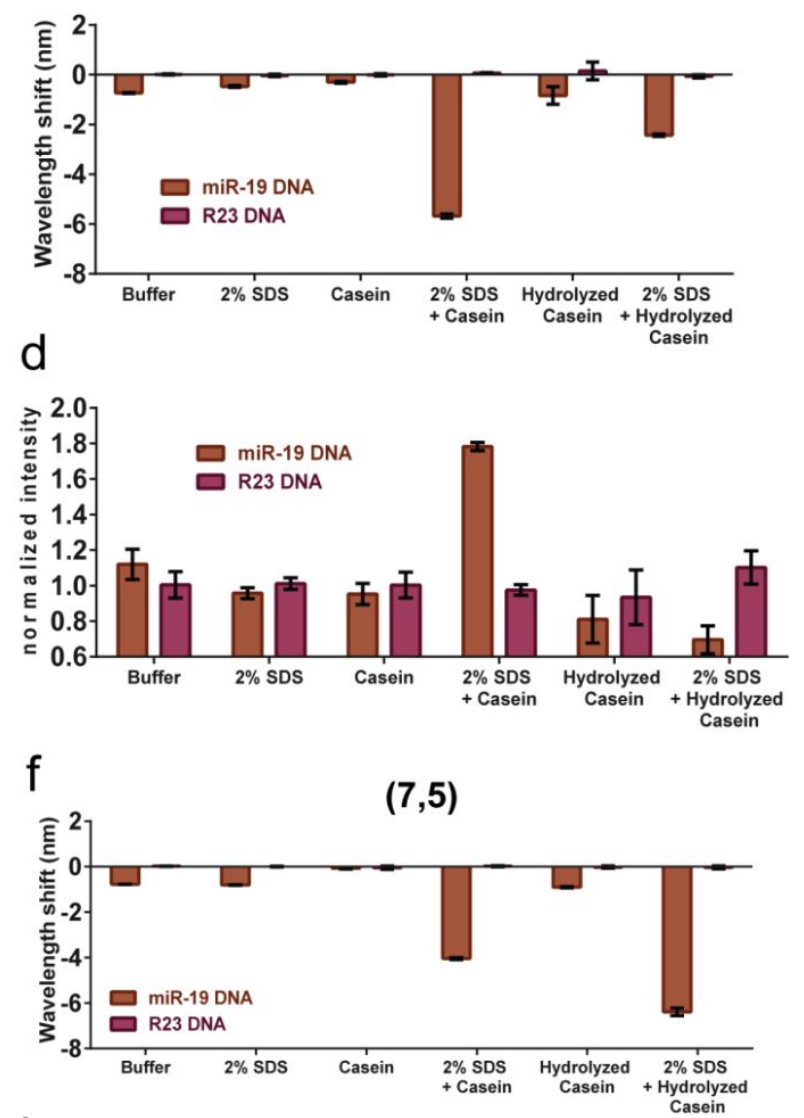

$\mathrm{h}$

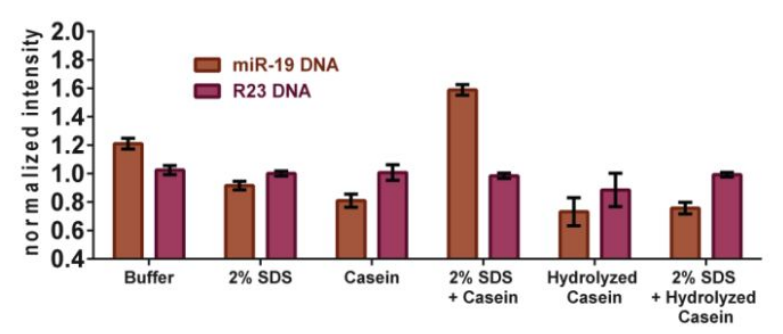

Figure S6: Effects of proteins and protein structure on $\mathrm{GT}_{15} \mathrm{miR} 19$ nanotube sensor response. $\mathrm{a}$. Wavelength shifting response of the $\mathrm{GT}_{15}$ mir19 nanotube sensor upon treatment with $1 \mu \mathrm{M}$ target miR-19 DNA or control R23 DNA in PBS buffer, 2\% SDS, $35 \mathrm{mg} / \mathrm{mL}$-globulins, and 2\% SDS with 35 $\mathrm{mg} / \mathrm{mL}$ overnight. $\mathbf{b}$. Wavelength shift of $\mathrm{GT}_{15}$ mir19 nanotube sensor after treatment with $1 \mu \mathrm{M}$ target miR-19 DNA or control R23 DNA in PBS, $2 \%$ SDS, $35 \mathrm{mg} / \mathrm{mL}$ casein, $2 \%$ SDS with $35 \mathrm{mg} / \mathrm{mL}$ casein, 35 $\mathrm{mg} / \mathrm{mL}$ hydrolyzed casein peptides, and $2 \%$ SDS with $35 \mathrm{mg} / \mathrm{mL}$ hydrolyzed casein peptides overnight. c. Intensity change corresponding to experiment in panel a. d. Intensity fold change corresponding to experiment in part b. Wavelength shift (e and $\mathbf{f}$ ) and intensity change ( $\mathbf{g}$ and $\mathbf{h}$ ) of the $\mathrm{GT}_{15}$ mir19 nanotube sensor response, focusing on two additional nanotube chiralities after overnight incubation with $1 \mu \mathrm{M}$ target miR-19 DNA or control R23 DNA in PBS, 2\% SDS, $35 \mathrm{mg} / \mathrm{mL}$ casein, $2 \%$ SDS plus 35 $\mathrm{mg} / \mathrm{mL}$ casein, $35 \mathrm{mg} / \mathrm{mL}$ hydrolyzed casein, or $2 \%$ SDS plus $35 \mathrm{mg} / \mathrm{mL}$ hydrolyzed casein. Demonstrating chirality differences in response to peptide length. 